ISSN 1112-9867

\title{
RELATIONSHIP BETWEEN POWER RESOURCES AND ORGANIZATIONAL CULTURE IN ARAS FREE ZONE
}

M. Ebadisharafabad ${ }^{1}$, M. Rasouli Gharetapeh ${ }^{1, *}$, T. Mousaloo $^{2}$ and Z. Rasouli Gharetapeh ${ }^{3}$

\author{
${ }^{1}$ Islamic Azad University, Depart of planning educational, Marand, Iran \\ ${ }^{2}$ Islamic Azad University, Depart of Educational Administration, Sanandaj, Iran \\ ${ }^{3}$ Ministry of EDUCATION, Marand, Iran
}

Published online: 15 May 2016

\begin{abstract}
This study intended to survey the relationship between power resource and organizational culture in Aras Free Zone. Statistical population consisted of all employees of Aras Free Zone $(\mathrm{N}=950)$. Samples population is selected using simple randomly method and Morghan table $(n=275)$. Methodology of this study is allied one objectively; it is a descriptive-survey in terms of data gathering method. Two standard questionnaires including organizational culture and French and Riyon power resource were used to gather data. Cronbuch Alpha coefficient value to calculate reliability was 0.79 and 0.89 respectively. It was used from Pearson correlation coefficient to analyze data. Findings showed that there was positive and significant relationship between power resource and organizational culture. Also, there was direct and significant relationship among legal, reward, expertise, referential power and organizational culture, while there was no significant relationship between compulsory power and organizational culture.
\end{abstract}

Keywords: power resource; legal power; reward power; expertise power; referential power; organizational culture.

Author Correspondence, e-mail: authorC@ gmail.com

doi: http://dx.doi.org/10.4314/jfas.v8i3s.232 


\section{INTRODUCTION}

In general culture, the power word has no pleasant conception and most peoples considered it as violence, autocracy and colonialism and have negative sense about it. Being detail in the conception of this word, we can find that the conception is not a negative phenomenon in nature and it has not an unpleasant conception such as violence, autocracy and colonialism. In many cases, the power word is used as a tool to exert pressure on others and or to colonize them. Therefore, it can be said that the power conception has no certain meaning either positive or negative. It has a general concept which how to use it can impose certain meaning to it. For example, if an organization use from power in order to lead its objectives and to provide organization interests and its members, it is a positive phenomenon and it use is not contraindicated. But, if the organizational power is used toward personal interests, it is considered as a negative phenomenon (Shafiee et.al. 2006).

Managers can use from different sources to exercise power. To Hersey and Blanchard, use of each of these resources depends on preparedness level of employees. In other words, the preparedness level of employees determines the type of power which manager must use of it (Hersey and Blanchard, 2002).

Katovski suggested that the employees who are under the influence of soft power resources have more job satisfaction than the subordinates who their managers use from hard power resources (cited by Gupta and Sharam, 2008).

In the present era which is called the era of technology, informatics, communications and knowledge explosion, managers play important role to create developments. Powerful managers are as skillful painters and sculptors who make pleasant sculpt and image from the organizations body. According to this mission, it would not be exaggerating to say that managers are the beginnings of many of changes and can create new world.

Managers as organizational leader select different ways of leadership to influence to their subordinates and to change their behavior in accordance with their wishes. Implementation of each of these leadership ways need to power supporting. Hence, organizations leaders need to use from each of these power types according to preparedness level of their employees. Preparedness means specified preparedness to do specified works which includes two main parts as ability and tendency. Ability means knowledge, experience and skill that the person owns to do specified work. Tendency means confidence level, commitment and motivation in a person to success in an activity (Hersey and Blanchard, 2002: 301). 
According to researches, $42 \%$ managers have no enough information about management styles that creates some problems in the interaction between managers and employees (Norouzi, 2000: 97).

\section{REVIEW OF LITERATURE}

\section{Culture}

Culture is a part of knowledge which is entered to the common mentality of individuals and or community. The meaning of knowledge here is not only mental awareness, imaginative or concessive, but it has common sense that covers the feelings, emotion, orientation, belief, habits and customs. Each type of awareness is located in the realm of culture when it finds common sense (Parsania, 2008: 52).

Culture includes beliefs, awareness, values, norms, customs and habits in this sense which transferred through education and find common sense. If the group which culture is realized among them is broad and widespread, culture is considered as common sense and if it is limited, it creates certain culture or sub-culture. Of course, it is possible that some certain subcultures be at the heart of a common culture. Common sense is a constraint that removes individual knowledge, certain knowledge, facts and affairs that are located out of the individual knowledge realm (Parsania, 2008: 52-53). Accordingly, culture has common and knowledgeable identity and it has various dimensions and levels.

Culture characteristics

According to researches about different cultures, it seems that beside differences, all cultures have characteristics that are as the followings (Zahedi, 2002):

- The culture is learnable. It is not a natural and innate property. It is a system that is learnable after the birth of Man.

- Culture is learned. Human can transfer his/her learned habits to others.

- Culture is a social phenomenon. The cultural habits have social roots and some people who live in the groups and societies shared them.

- The culture is a mental and visual phenomenon. The group habits which the culture is created from it are considered as norms, behavioral patterns or intellectual aspirations.

- The culture is not pleasant. Any culture which cannot determine the highest aim of life, it cannot meet higher ideals of life. The cultural elements can be sustained as long as they give pleasure to community. 
- The culture can be adapted. It can be changed and its change comes with adaptation and compatibility.

- The culture is unique-making. Its elements tend to create integrated and adaptive body and this adaptive body need to time to be created.

\section{Organizational culture}

Organizational culture refers to main values, assumptions and interpretations in the approaches that specify organizational properties that are grouped in type. They include ethnic properties, elitism, market and hierarchies (Koeen, 1999). Culture refers to all intellectual and material works in a society (Sadeghpour, 1996).

Organizational culture refers to a collection of shared organizational conceptions and valuemaking systems that forms the behavior and attitudes of members of organization and controls the technological outputs of an organization and its general performance (Monavaryan and Sharifi, 2008).

\section{Power}

Power refers to possibility of imposing ones will on another collective behavior (Galbriat, 1987: 23). Or, it is said that "power means the option of imposing ones will on others either optional or coercive (Agha Bakshi, 1987: 203). With a little care, we can find that in fact, this definition and some other definitions see it in the political perspective, but it has humanitarian-social conceptions which the political power is one of its branches.

Now, according to above analysis, we can define power in general and in particular: The power of every entity (including natural, virtual or social entity) refers to origin and behavior which play positive role in their formation goal. In other words, the power is the origin of creation of works in which we expect (Eskandari and Darabkelayee, 2004: 56).

Legal power: it refers to the competency of the manager in decision-making based on its rank in the organization (heresy and Blanchard, 2002).

Rewarded power: To imagine necessary ability to provide what is individual's favorite property (Hersey and Blanchard, Ibid).

Compulsory power: To imagine necessary ability to punish or the consequences of nonperformance.

Referential power: To imagine that there is pull attraction and interaction with another person.

Expertise power: To imagine the manager has related experience and expertise (Hersey and Blanchard, Ibid). 
In efficient organizations, the power is grown by intelligent people with careful (ShermerHorn and Azbourn, 1999: 207).

According to Bertrand Russell, as the energy of a fundamental and basic thing lies in physics science, the power is also has a basic knowledge in social science (Hikes and Gullet, 2005).

Parsons define the power as a social system in functions in favor of collective goals. In his perspective, power is a exchange tool which is not desirable by itself and has no value to use, but it is desirable to exchange, it means that it is desirable for the possession of things that are desirable by themselves (Golipour, 2001).

Also, Dubrin define the power as the ability to influence on decision-makings and resource control (Dubrin, 2001).

According to Pero, organizations create power and the power are created through different resources and in different forms, it is opposed and it surely is used (Scott, 2003: 389).

\section{Power resources}

There are different orientations and attitudes about power resource. Some believed that iy is the source of evil and corruption. In their perspectives, power exercise leads to Machiavelli, i.e. putting aside all principles and sacrifices all ethical laws toward to achieve to success and benefit. Others believed that the power is a vague and complex phenomenon, so that individuals prefer to deal with it seriously. But recently, many people believed that the power is a natural phenomenon, it is a necessary element in an organization. According to Lorenz, the power in a collection is normal and it is necessary for its performance (Hikes and Gullet, 2005: 18-23).

During previous years, social psychology experts give more attention to classify the power resources. The French and Rion classification is the most known of them.

French and Rion have identified five resources for power. These power aspects exist in different forms of human relations. In an organization, it is possible that there is any source of power in many different levels. These power resources are as the followings:

- Expertise power: It is yield from techniques, skills and knowledge (Gemmy, 2001). Expertise has become to one of the most powerful resources of leveraging, because the world takes steps toward high technology. Since things are more expertized, organizations are more dependent to experts in order to achieve to their objectives (Robbins, 2005). In management field, if the manager has related academic field, experience and related expertise, his/her power arising from his/her expertise (Azizi et.al, 2009). 
- Legal power: This power is yield from the status and reputation. Having this power means having ability to influence of managers on others only due to their power arising from their status (Anderson et.al, 1998).

- Compulsory power: It is created when the individual has ability to punish one or to harm one physically or mentally (Mourhed, 2003). The compulsory power is the one that force the individuals to do things that is against their will. Compulsory lead to physical damages, although its main objective is obedience (Streaker, 2005). Also, the image arising from necessary ability to punish or also arising outcomes from nonperformance are called compulsory power (Azizi et.al, 2009).

- Referential power: Image arising from attraction and tension between individuals is considered as referential power (Ibid, 2009). The so-called power belongs to those leaders that have desirable characteristics, charismatic and high reputation. There is no need to exercise power like expertise power (Haghigi, 2003). Also, compulsory power is created when the one who holds this power is respected by others (SharifZadeh, 2003).

- Reward power: If the one can give the thing which is valuable to other, or he/she can foreclose a thing that has negative value to other, has the power based on reward (Jansoon, 2004). The nature of reward power of managers depends on organization careers and policies partially (Seyyed Javadin, 2004).

- Information power: Exposure to people situation, events, other facts, access to information and resources is the source of influence to help people or organizational entities through overcome on uncertainty. Generally, individuals that have information that others deprive, have significantly information power (Andersoon and Cepperyano, 1998: 242).

Other managers use power to achieve to influence in individuals in work environment which it arises from organizational and individual resources. These resources can be divided into job power and personal power (Hersey Koich, 2002).

Based on job power, three power bases is available for manager: reward power, compulsory power and legal power. Personal power includes expertise power and referential power (Iran Nejag Parizi, 2002:25)

Relation pattern of power and culture

1. Necessary of relation of pattern of culture with other dimensions of society 
It is necessary to study in detail the relation between culture and other dimensions of society to achieve specified classification in this dimension due to multi-dimensionality nature of culture and its interweaving nature with other dimensions of society. Therefore, it is necessary to design a simple pattern in which the relation between culture and other dimensions of society is described and thus how to interact and effects of culture on other dimensions of society is specified, before designing the classification pattern of cultural subjects. Designing such pattern has importance when we know that although culture has extensive nature to the extent nature problems of society, it should be prepared to manage within other dimensions of society. As in the society specified entities have been in the charge of cultural affairs and it shows the culture importance and the need to attempt to solve related problems and to identify cultural changes in the society. So, in confronting with cultural themes in the society, we confront with this problem that we cannot consider some parts of society as cultural part, because we can see cultural effects in all issues of society including political and economic issues in one hand, and that those issues are formed based on special culture. And in other hand, division necessity of labor in society management requires that cultural management is applied in specified area unlike political and economic management. Such duality and contraction has caused that determination of cultural management fate is challenged. Setting cultural subjects system is successful when this problem was solved previously and fixing this problem is possible if the relation between culture and other dimensions of society is specified and hoe it effects and is influenced on or by other dimensions of society is determined (Pirouzmand and Jamali, 2006:11).

2. How to impact and unaffected by dimensions with each other

According to surveys, each area of political, cultural and economic fields is continuously intertwined. Based on this study, it has become clear that among five components related to political area, two components are related to political and cultural area, i.e. cultural policy and political culture commonly are considered in political and cultural areas. Also, economic policy and political economic is present commonly in the political and economic areas. We encounter with such interference in cultural area, that cultural economic and economic culture are two common components between culture and economic areas. In economic area, two components of political economic and economic policy are common too like as two components of cultural economic and economic culture which are common with cultural area. These subscriptions means extends a 
dimension in another dimension which in fact clears the effects of society dimension on each other or their interactions that has importance in the study of culture, policy and economic areas (Ibid, 2006: 11-18).

3. Scope of cultural affairs based on cultural relation model

Drawing the model of relation of culture with political and economic areas make clear the following cases:

- In cultural management, we cannot ignore the cultural policy which is political in nature and cultural economic which is economic in nature. But, we should attend to cultural policy and economic policy in addition to cultural affairs. It must be established concreted relation among these three dimensions.

- Also, we should not ignore the effectiveness of cultural area on political and economic areas. Although political culture and economic culture related to policy and economic areas, they are cultural dimension in nature. Thus, elongation of cultural area to the political area in cultural area in the form of cultural policy and effectiveness of economic area in cultural area in the form of cultural economic are considered. So, the matrix of relation of culture with political and economic areas shows the continuity of these dimensions and organizing in cultural area. Therefore, political culture, cultural culture and economic culture should be organized in the construction and organization of culture (Rezaie, 2007: 317).

\section{RESEARCH HYPOTHESIS}

\section{Main hypothesis:}

Mangers power resource related to organizational culture of employees in Aras Free Zone.

\section{Sub-Hypothesis}

- There is a relationship between legal power of managers and organizational culture of employees in Aras Free Zone.

- There is a relationship between reward power of managers and organizational culture of employees in Aras Free Zone.

- There is a relationship between expertise power of managers and organizational culture of employees in Aras Free Zone.

- There is a relationship between compulsory power of managers and organizational culture of employees in Aras Free Zone. 
- There is a relationship between referential power of managers and organizational culture of employees in Aras Free Zone.

\section{Methodology}

This study is an applied one objectively and it is a descriptive-survey based on the method of gathering data. Statistical population consisted of all employees of Aras Free Zone ( $\mathrm{N}=950)$ which sample size is selected using Morghan table and by simple ransom sampling method. The standard questionnaire of organizational culture and French and Ryion questionnaire were used to gather data. The Cronbach Alpha value for these questionnaires was 0.797 and 0.89 respectively. Pearson correlation coefficient was used to test hypothesis using SPSS software.

\section{FINDINGS}

\section{Normality test}

In this section, test of normality of legal, reward, expertise, referential power of managers and organizational culture are considered. To do this, we used from Kolmogorov-Smirnov test. As can be seen in table 1, the significant level of all variables of power resources including legal, reward, expertise, compulsory and referential power of managers and also organizational culture is more than 0.5 , so we can say with $95 \%$ confidence that these variables have normal distribution.

Table 1. Kolmogorov-Smirnov test

\begin{tabular}{cccccccc}
\hline & $\begin{array}{c}\text { Power } \\
\text { resource }\end{array}$ & legal & reward & expertise & compulsory & referential & $\begin{array}{c}\text { Organizational } \\
\text { culture }\end{array}$ \\
\hline $\begin{array}{c}\text { The test } \\
\text { statistic }\end{array}$ & 0.786 & 0.899 & 1.032 & 1.071 & 1.267 & 0.808 & 1.106 \\
\hline $\begin{array}{c}\text { Significant } \\
\text { level }\end{array}$ & 0.175 & 0.395 & 0.096 & 0.201 & 0.081 & 0.531 & 0.132 \\
\hline number & 275 & 275 & 275 & 275 & 275 & 275 & 275 \\
\hline
\end{tabular}

First Hypothesis: Power resources of managers related to organizational culture of employees in Aras Free Zone.

To test the relation between power resources with organizational culture of employees, it is used from Pearson correlation coefficient. 
Table 2. The correlation of power resources and organizational culture

\begin{tabular}{cc}
\hline Correlation coefficient & Significant level \\
\hline 0.815 & 0.000 \\
\hline
\end{tabular}

According to table 2, the correlation coefficient is 0.815 which indicating good and partially strong correlation and given to obtained significant level which is 0.000 and is less than 0.05 , so we can conclude that there is direct and significant relationship between power resources and organizational culture of employees.

Second Hypothesis: Legal power of managers related to organizational culture of employees of Aras Free Zone.

To test the relation between legal power of managers and organizational culture, it is used from Pearson correlation coefficient.

Table 3. The correlation of legal power of managers and organizational culture

\begin{tabular}{cc}
\hline Correlation coefficient & Significant level \\
\hline 0.786 & 0.000
\end{tabular}

According to table 3 , the correlation coefficient is 0.786 indicating a good and partially strong relation and given to obtained significant level ( $\mathrm{sig}=0.000)$ which is less than 0.05 , so there is direct and significant relation between legal power of managers and organizational culture of employees.

Third Hypothesis: Reward power of managers related to organizational culture of employees of Aras Free Zone.

To test the relation between reward power of managers and organizational culture, it is used from Pearson correlation coefficient.

Table 4. The correlation of reward power of managers and organizational culture

\begin{tabular}{cc}
\hline Correlation coefficient & Significant level \\
\hline 0.639 & 0.000
\end{tabular}

According to table 4 , the correlation coefficient is 0.639 indicating a good and partially strong relation and given to obtained significant level $(\mathrm{sig}=0.000)$ which is less than 0.05 , 
so there is direct and significant relation between reward power of managers and organizational culture of employees.

Forth Hypothesis: Expertise power of managers related to organizational culture of employees of Aras Free Zone.

To test the relation between expertise power of managers and organizational culture, it is used from Pearson correlation coefficient.

Table 5. The correlation of expertise power of managers and organizational culture

\begin{tabular}{cc}
\hline Correlation coefficient & Significant level \\
\hline 0.587 & 0.000
\end{tabular}

According to table 5, the correlation coefficient is 0.587 indicating a good and partially strong relation and given to obtained significant level ( $\operatorname{sig}=0.000)$ which is less than 0.05 , so there is direct and significant relation between expertise power of managers and organizational culture of employees.

Fifth Hypothesis: Compulsory power of managers related to organizational culture of employees of Aras Free Zone.

To test the relation between compulsory power of managers and organizational culture, it is used from Pearson correlation coefficient.

Table 6. The correlation of compulsory power of managers and organizational culture

\begin{tabular}{cc}
\hline Correlation coefficient & Significant level \\
\hline-0.012 & 0.893
\end{tabular}

According to table 6 , the correlation coefficient is -0.012 indicating a very weak relation and given to obtained significant level ( $\mathrm{sig}=0.893$ ) which is more than 0.05 , so there is no significant relation between compulsory power of managers and organizational culture of employees.

Sixth Hypothesis: Referential power of managers related to organizational culture of employees of Aras Free Zone.

To test the relation between referential power of managers and organizational culture, it is used from Pearson correlation coefficient. 
Table 7. The correlation of referential power of managers and organizational culture

\begin{tabular}{cc}
\hline Correlation coefficient & Significant level \\
\hline 0.386 & 0.000
\end{tabular}

According to table 7 , the correlation coefficient is 0.386 indicating a moderate relation and given to obtained significant level (sig=0.000) which is less than 0.05 , so there is direct and significant relation between referential power of managers and organizational culture of employees.

\section{RESULT AND DISCUSSION}

Study the relation between power resources and culture related to the subjects of culture sociology. The culture related to other political and economic areas motivationally. According to systematic approach between culture and power, there is an interaction between them. The culture effect on economic, policy and other social areas inherently. Since culture is a product of social interaction, it is considered as a part of social world and accordingly, it is related to important power lines which govern on social environment. The power and culture related to each other as inseparable and we cannot separate the culture analysis from policy and relations based on power. That is why the culture issue is a series governmental issue and it is necessary that the ways in which the culture is related to power analyzed in detail. To depict such relation requires to provide a pattern in which how to interact all dimensions of society with each other is designed. The results using Pearson correlation coefficient suggested that there is positive and significant relationship between power resources and organizational culture. Also, it is observed a direct and significant relationship among legal, reward, expertise, referential power and organizational culture. So, increasing power resources and improvement of referential power of managers, the culture of organizations is enhanced, while there is no significant relationship between compulsory power and organizational culture.

\section{RESOURCES}

[1] Amjadi, Zahra (2000). Study the enjoying amount of managers from five power resources in departments of Rafsanjan city, M.A thesis, Islamic Azad University of Kerman.

[2] Eskandari, Mohammad Hossein; Darabkelayee, Esmaiel(2005). A study on power fields, Qom, Research institute of Howzeh and University. 
[3] Galbrait, Jean Gent (1987). Power autopsy, translator: Shahsa, Ahmad.

[4] Haghighi, Mohammad Ali (2001). Organizational behavior management, Termeh publication, Tehran.

[5] Hikes, Herbert; Goulet, Siri (2005). Organization and management theories, translation by Gouel Kohen, third publication, Tehran. Douran publication.

[6] MAhmmudi, Zahrasadat (2008). Study the relation between power resources and ways to overcome to employees resistance among managers of Esfahan Universities and medical Universities of Esfahan in academic year o 2007-2008. M.A. thesis, Esfahan University, educational and psychological colleges.

[7] Movaryan, Abbas; Ghorbani, Mohammad Hossein, Sharifi, Moslem (2008). Organizational culture (based on Denison model). Shiraz: Shiraz University.

[8] Parsania, Hamid (2008). Relation between Science and religion, cultural strategy, First year, second number, secretariat of High council of Cultural Revolution center.

[9] Pirouzmand, Alireza; Jamali, Mostafa (2006). Classification pattern of subjects in cultural engineering of Iran, secretariat of High council of Cultural Revolution center.

[10] Pourian, Khodayar (1997). Study the relation between using power kinds by manager and school organizational environment, M.A. thesis, Alameh Tabatabie University, Psychological and educational science college.

[11]Rahman Seresht, Hossein; Fayazi, Marjan (2008). Study the relation between power assumption and policy studies of organization with commitment and performance of employees, Human-social sciences, special to management, eighth year, No: 29.

[12] Sadeghpour, Aboulfazl (1996). Collection of papers related to engineering in society, first publication, Tehran, Governmental management education center.

[13] Sharyati, j (2002). Study the relation between use of power kinds by school principals in high schools of Shiraz city from teachers perspectives, M.A thesis, Tehran, teacher training university.

[14] Sohrabi, Nafiseh; Shah Talabi, Badri; Ahmadi, Gholamreza (2009). Relation between power resources of managers and organizational culture kind in high schools of Khomein city, scientific-survey quarterly of Islamic Azad University of Khorasegan unit (esfehan), sixth year, No: 21. PP. 79-100.

\section{How to cite this article:}

Ebadisharafabad M, Rasouli Gharetapeh M, Mousaloo T and Rasouli Gharetapeh Z. Relationship between power resources and organizational culture in Aras free zone. J. Fundam. Appl. Sci., 2016, 8(3S), 509-521. 